\title{
Assessment of COPD burden through its stages
}

\author{
Assem Foad Elessawy (1), Radwa Ahmed Elhefny (2), Fatmaalzahraa Saad \\ Abdalrazik (3), Sarah khaled Alhadidi (3)
}

(1) Chest Departement, Faculty of medicine, Fayoum university.

(2) Chest Departement, Faculty of medicine, Fayoum university.

(3) Chest Department, Faculty of medicine, Helwan university.

(4) Chest Departement, Faculty of medicine, Fayoum university. Corresponding author: Dr: Sarah Khaled mail:doctorsarahadidi@gmail.com Tel: 01015818035

\section{Abstract}

\section{Objective:}

This study aims to assess the increasing social, mental, and health burden on COPD patients through its different stages.

\section{Patients and methods:}

The present study included 300 candidates functionally diagnosed of having COPD according GOLD 2017. All patients were subjected to history taking, clinical examination, BMI and free fat mass index (FFMI) assessment, spirometry before and after bronchodilator testing, and questionnaires, such as COPD Assessment Test, Clinical COPD Questionnaire, and Hospital Anxiety and Depression Scale.

\section{Results:}

The study included 300 patients with COPD who are current smokers. Overall, $98 \%$ of them were males, and all were older than 40 years. Patients were classified into three groups: mild, moderate, and severe. Amount of cigarettes was found to be directly proportionate to COPD burden. Regarding weight burden, obesity wasn't found to be a sign of increasing burden of the disease, while cachexia was found in the more severe COPD stage. We found that dyspnea and other symptoms of the disease were found to be increased with increased disease severity indicating more health burden with the more severe COPD stages. Also ,Mental health status had a direct positive correlation with COPD severity.

\section{Conclusion:}

COPD carries high health, social, functional and psychological burden on the patient and that burden is directly proportionate to COPD severity.

\section{Keywords:}

Chronic obstructive pulmonary disease, smoking, burden.

\section{Introduction:}

Chronic obstructive pulmonary disease (COPD) is a common, preventable, and treatable disease, characterized by the irreversible airflow limitation secondary to alveolar and/or airway changes [1].

COPD is considered to be a major cause of mortality and morbidity worldwide. This causes increased social and economic burden [1]. In addition to adding high health care expenses, COPD is considered a burden regarding impaired quality of life and disability [2].

Few studies have been done to assess COPD burden in developing countries [3], and the prevalence of COPD morbidity indices is underestimated, as it is not correctly measured 
[4]. The impact of COPD on health and quality of life is considerable, particularly in patients with severe stages [4].

Patients with COPD experience respiratory symptoms and physical affection and often have several comorbidities. As a result of that, they often have affected health status or healthrelated quality of life (2).

The effect of COPD is stronger on the physical than the mental aspects of health status according to "The impact of COPD on health status: findings from the BOLD study" study. Mental health status was mainly related to the level of dyspnoea according to the same study (5).

Anxiety and depression are common in patients with COPD, and have an impact on the psychosocial aspects of the management of this disease. Prognostic studies involving patients with COPD have mostly focused on physiologic variables, with less attention given to the psychological aspects of the disease [5].

In this study, we assessed the increasing social, mental, and health burden on COPD patients through its different stages.

\section{Patients and methods}

\section{Study design}

This is a case-control study that was conducted in chest department, Fayoum University hospitals and Helwan University hospitals, through November 2017-April 2019. Ethics approval was obtained from the Ethical Committee of the Faculty of Medicine, Fayoum University, Egypt, June 2017. Consent was obtained from all the patients.

The study design was approved by the Scientific Ethics Committee of Faculty of Medicine, Fayoum University, Egypt, on June 2017.

\section{Study population}

The study included 300 patients, with 100 cases in each severity group (mild, moderate, and severe) of COPD, diagnosed according to
GOLD guidelines 2017 [8].Very severe group was not included owing to deficiency of cases, and the already found cases were incapable of fulfilling the questionnaires. All patients were selected from Helwan University Hospital outpatients departments according to the following inclusion and exclusion criteria.

\section{Inclusion criteria}

(1) Patients diagnosed as COPD according to GOLD guidelines 2017.

(2) 40 years of age or older.

\section{Exclusion criteria}

(1) Terminal illnesses, for example, malignancies, chronic kidney disease, and chronic liver disease.

(2) Diagnosed with old or current psychiatric condition.

(3) Exacerbation during the study.

\section{Analytical method}

All candidates were subjected to the following:

(1) Full history taking and full clinical assessment.

(2) BMI and FFMI.

(3) Dyspnea score according to modified Medical Research Council scale (mMRC).

(4) Questionnaires.

\section{Chronic obstructive pulmonary disease assessment test}

All patients completed this questionnaire in Arabic language. COPD Assessment Test (CAT) is designed to assess the effect of COPD on a candidate's life, and how this effect changes with time. CAT is simple and gives clinicians the data that helps them to give their patients' better management of their condition [9]. 


\section{Clinical chronic obstructive pulmonary disease questionnaire}

This patient questionnaire included a validated Swedish version of the Clinical COPD Questionnaire (CCQ) in Arabic language. The CCQ consists of ten questions distributed in three domains: symptoms, mental state, and functional state. Observed symptoms of daily life owing to the lung disease. The questions apply to the previous week and use a sevenpoint scale from 0 to 6 [10].

\section{Hospital Anxiety and Depression Scale}

The patients answered the Hospital Anxiety and Depression Scale (HADS) questionnaire translated to Arabic Language. HADS is a questionnaire composed of statements relevant to either generalized anxiety or depression, the latter being largely composed of reflections of the state of anhedonia [11].

(5) Spirometry before and after bronchodilator testing.

Dynamic spirometry was performed using MIR Spirobank II Spirometer (MIR Medical International Research, Roma, Italy). The test was done before and after nebulization of $5 \mathrm{mg}$ of salbutamol sulfate with $2 \mathrm{ml}$ saline $0.9 \%$ for 3 min All cases with values of post-forced expiratory volume in $1 \mathrm{~s}$ (FEV1) less than $80 \%$ of the expected value and post-FEV1/forced vital capacity less than 0.7 without significant improvement post bronchodilator inhalation were included in our study.

\section{Statistical analysis}

Microsoft excel 2013 was used for data entry. Data analysis was done by using the statistical package statistical package for the social sciences, version 25. All statistical calculations were carried out using the computer program SPSS (SPSS Inc., Chicago, Illinois, USA) release 15 for Microsoft Windows (2006). Data were summarized using mean, SD, median, minimum, and maximum in quantitative data and using frequency (count) and relative frequency (percentage) for categorical data. Comparison among the three groups regarding dyspnea scale was done using the nonparametric test, Kruskal-Wallis $\mathrm{H}$ test, and differences between groups together were done by MannWhitney $U$ test (categorical variables). Comparison among the three groups regarding other numerical variables was done by one-way analysis of variance test (Tukey HSD). Pearson correlation test was used to estimate correlation between numerical variables. A P value less than 0.05 was considered statistically significant.

\section{Results}

This research included 300 candidates clinically and functionally diagnosed as having COPD. Of the 300 cases, 294 were males, and all were above 40 years old. The study population's mean age was 57.69 years. The mean BMI was 27.06, and mean FFMI was 18.86. All the patients were current smokers, and their mean smoking index (SI) was 66.39 pack/year (Table 1).

The study cases were classified into mild moderate and severe according to GOLD 2017 classification. We did not enroll any cases with very severe COPD in the current study. The mean age in the mild group was 54.37, BMI was 2.63, mean FFMI was 19.48, and mean SI was 23.11. In moderate group, the mean age was 57.46, mean BMI was 27.12, mean FFMI was 19.00, and mean SI was 61.19. In the severe group, mean age was 61.30 , mean BMI was 26.51, mean FFMI was 18.16, and mean SI was 114.68. The correlation of these variables to COPD severity was found to be statistically significant ( $\mathrm{P}>0.0001$; Table 2).

All study population underwent the CCQ, CAT, and HADS.

In the current study, we correlated BMI and FFMI with the three COPD stages, SI, mMRC grades, CAT score, the three domains of CCQscore, and HADS.

\section{Table 1: Descriptive Statistics of all study population}


ISSN: 2536-9482 (Online) Fayoum University Medical Journal Elessawy et al., 2021,7(1), 920

\begin{tabular}{||c|l|c|c|l||}
\hline & N & Minimum & Maximum & ean \pm SD \\
\hline Age & 300 & 40 & 85 & $69 \pm 9.469$ \\
\hline BMI & 300 & 15.30 & 49.60 & $0622 \pm 5.87072$ \\
\hline FMI & 300 & 11.88 & 29.91 & $8641 \pm 2.90678$ \\
\hline $\begin{array}{c}\text { Smoking } \\
\text { Index }\end{array}$ & 300 & 7.00 & 162.00 & $3900 \pm 40.02432$ \\
\hline
\end{tabular}

Table 2: Descriptive statistics of study variables through each group

\begin{tabular}{||c|c|c|c|c|l||}
\hline \multirow{2}{*}{} & \multicolumn{3}{|c||}{ DIAGNOSIS } & \multirow{2}{*}{ P } & \multirow{2}{*}{ SIG } \\
\cline { 2 - 5 } & Mild & Moderate & Severe & & \\
\cline { 2 - 6 } & Mean \pm SD & Mean \pm SD & Mean \pm SD & & \\
\hline \multirow{2}{*}{ BMI } & $27.632 \pm 5.059$ & $27.12 \pm 5.488$ & $26.510 \pm 6.904$ & $\mathbf{0 . 2 0 9}$ & NS \\
\hline FFMI & $19.48 \pm 2.810$ & $19.00 \pm 2.658$ & $18.162 \pm 3.097$ & $\mathbf{0 . 0 0 2}$ & HS $* *$ \\
\hline Smoking Index & $23.113 \pm 7.42$ & $61.19 \pm 14.6259$ & $114.68 \pm 17.63$ & $\mathbf{0 . 0 0 0}$ & HS \\
\hline
\end{tabular}

$* *$ HS (highly Significant) $\leq 0.05 * \mathbf{N S}$ (Non significant) $\geq .05$

There was no statistically significant difference between mild, moderate and severe cases as regard gender and BMI (Body Mass Index), as shown in (Table 2). Although there was a highly statistically significant difference between mild, moderate and severe cases as regard age, FFMI (Free Fat Mass Index). Mean smoking index increased with increasing COPD severity. (61.30 \pm 7.681 and 114.68 \pm 17.635$)$, while mean FFMI was decreasing with increasing COPD severity (19.48 \pm 2.810$)$ (Table 2).

\section{Figure 1:}

\section{Mean BMI in COPD stages}

$\mathrm{P}$ value $=0.209$

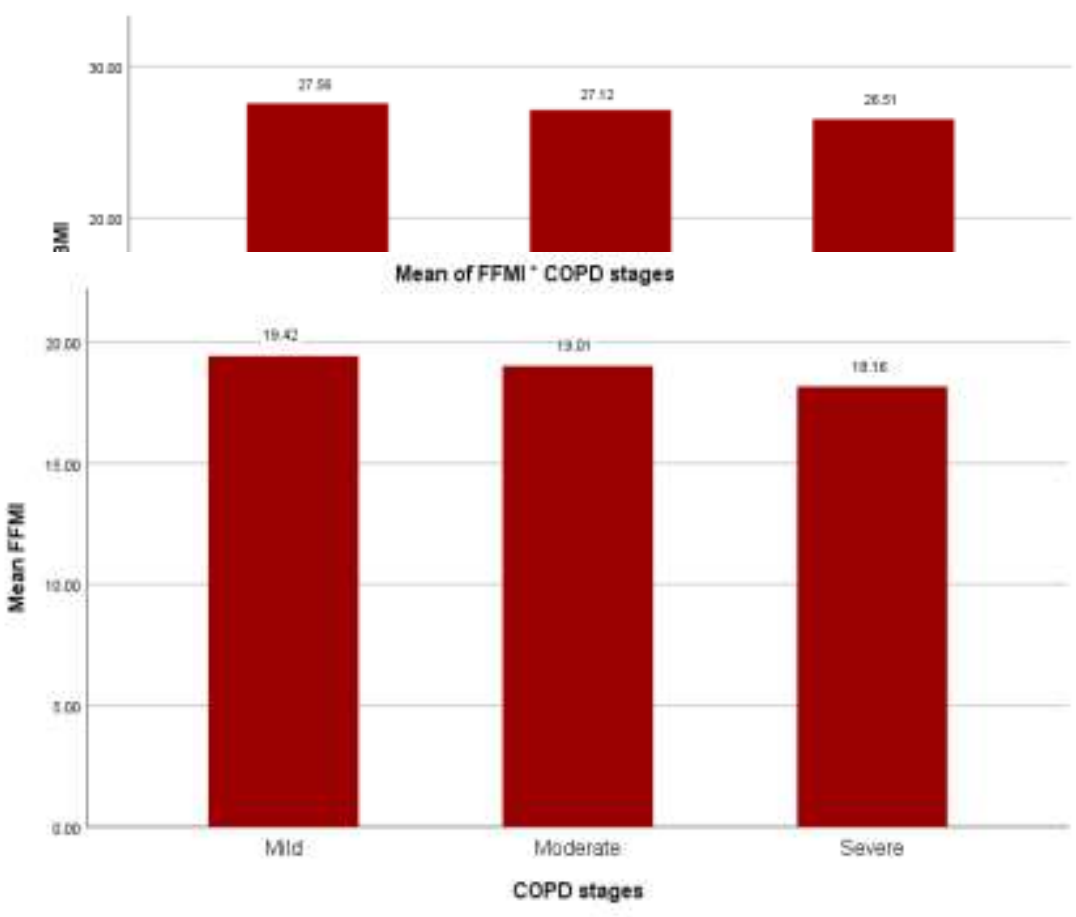

Figure 2: 
ISSN: 2536-9482 (Online) Fayoum University Medical Journal Elessawy et al., 2021,7(1), 920

\section{Mean FFMI in COPD stages}

$$
P \text { value }=0.002
$$

Table 3: Mean FFMI in correlation to COPD stages.

\begin{tabular}{|c|c|c|c|c|}
\hline & \multicolumn{2}{|c|}{ COPD stages } & \multirow{2}{*}{\begin{tabular}{|c|} 
P value \\
.561 \\
\end{tabular}} & \multirow{2}{*}{\begin{tabular}{|l|} 
Sig \\
NS*
\end{tabular}} \\
\hline \multirow{6}{*}{ FMI } & \multirow[t]{2}{*}{ Mild } & Moderate & & \\
\hline & & Severe & .006 & HS** \\
\hline & \multirow[t]{2}{*}{ Moderate } & Mild & .561 & NS* \\
\hline & & Severe & .095 & NS* \\
\hline & \multirow[t]{2}{*}{ Severe } & Mild & .006 & HS** \\
\hline & & Moderate & .095 & NS* \\
\hline
\end{tabular}

There was high statistical significance was seen between mild and severe COPD stages as in table 3.

Table 4: Correlation of Smoking index and stages of COPD

\begin{tabular}{|c|c|c|c|c|}
\hline \multirow{8}{*}{$\begin{array}{l}\text { Smoking } \\
\text { index }\end{array}$} & \multicolumn{2}{|c|}{ COPD stages } & \multirow{2}{*}{\begin{tabular}{|l|l}
$\mathbf{P}$ \\
.000 \\
\end{tabular}} & Sig \\
\hline & Mild & Moderate & & \multirow{6}{*}{$\mathrm{HS}^{* *}$} \\
\hline & & Severe & .000 & \\
\hline & \multirow[t]{2}{*}{ Moderate } & Mild & .000 & \\
\hline & & Severe & .000 & \\
\hline & \multirow[t]{2}{*}{ Severe } & Mild & .000 & \\
\hline & & Moderate & .000 & \\
\hline & \multicolumn{3}{|c|}{$* *$ HS (highly significant) $\leq 0.05$ level. } & \\
\hline
\end{tabular}

Figure 3: Mean smoking index in the three COPD stages 
ISSN: 2536-9482 (Online) Fayoum University Medical Journal Elessawy et al., 2021,7(1), 920

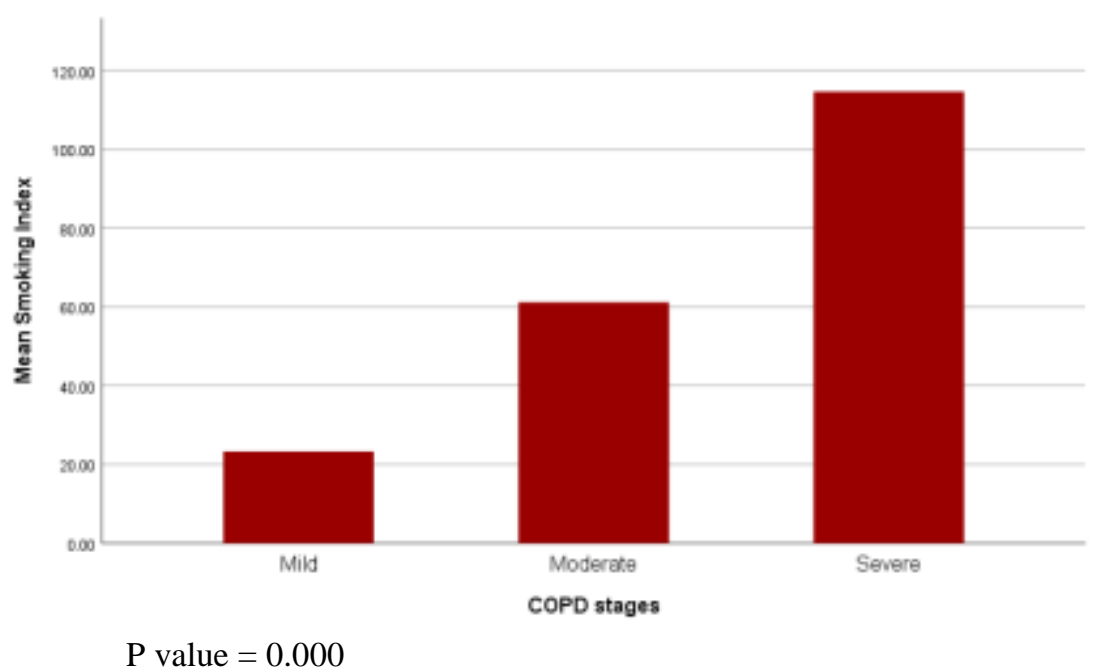

High statistical significance was detected between smoking index and all COPD stages as shown in table 4 and figure 3 .

Table 5: Frequencies of mMRC grades in COPD stages

Figure 4: mMRC grades through COPD stages

\begin{tabular}{|c|c|c|c|c|c|c|c|c|}
\hline & & \multicolumn{5}{|c|}{ mMRC Grades } & \multirow[t]{2}{*}{ Total } & \multirow[b]{2}{*}{ value } \\
\hline & & Grade 0 & Grade 1 & Grade 2 & Grade 3 & Grade 4 & & \\
\hline \multirow{6}{*}{$\begin{array}{l}\text { COPD } \\
\text { stages }\end{array}$} & \multirow[t]{2}{*}{ Mild } & 8 & 48 & 42 & 2 & 0 & 100 & \multirow{6}{*}{0.05} \\
\hline & & $8.0 \%$ & $48.0 \%$ & $42.0 \%$ & $2.0 \%$ & $0.0 \%$ & $0.0 \%$ & \\
\hline & \multirow[t]{2}{*}{ Moderate } & 0 & 28 & 50 & 22 & 0 & 100 & \\
\hline & & $0.0 \%$ & $28.0 \%$ & $50.0 \%$ & $22.0 \%$ & $0.0 \%$ & $0.0 \%$ & \\
\hline & \multirow[t]{2}{*}{ Severe } & 0 & 2 & 18 & 58 & 22 & 100 & \\
\hline & & $0.0 \%$ & $2.0 \%$ & $18.0 \%$ & $58.0 \%$ & $22.0 \%$ & $0.0 \%$ & \\
\hline
\end{tabular}

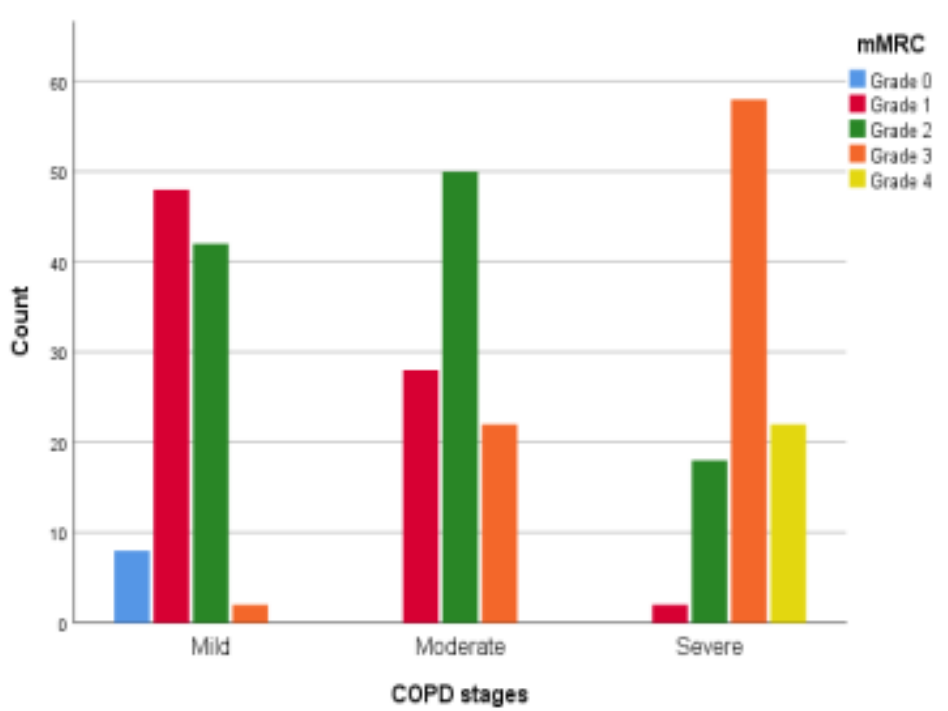


ISSN: 2536-9482 (Online) Fayoum University Medical Journal Elessawy et al., 2021,7(1), 920

There was no significant Correlation between mMRC dyspnea scale and COPD stages shown in (Table 5).

Table 6: Descriptive statistics of all questionnaires data through the

\begin{tabular}{||l|c|l|c|l|}
\hline PD stages & CAT & CCQ total & HADS depression & IADS anxiety \\
\cline { 2 - 5 } & Mean \pm SD & Mean \pm SD & Mean \pm SD & Mean \pm SD \\
\hline Mild & $8.14 \pm 2.174$ & $15.12 \pm 4.852$ & $6.58 \pm 3.960$ & $7.26 \pm 3.645$ \\
\hline Moderate & $13.28 \pm 3.303$ & $24.04 \pm 3.303$ & $6.68 \pm 4.528$ & $8.06 \pm 4.775$ \\
\hline Severe & $30.86 \pm 3.782$ & $45.74 \pm 5.486$ & $12.32 \pm 4.694$ & $13.98 \pm 3.832$ \\
\hline Total & $17.43 \pm 10.240$ & $28.30 \pm 13.684$ & $8.53 \pm 5.148$ & $9.77 \pm 5.082$ \\
\hline
\end{tabular}

Table 6 shows mean and standard deviation of the scores of the three questionnaires done in the study through the three study groups (COPD stages).

Table 7: Correlation between CAT score, total CCQ, HADS depression score and HADS anxiety score and COPD stages

\begin{tabular}{||l|l|l|l|l|c|}
\hline \hline \multicolumn{2}{||}{} & CAT & CCQ total & HADS depression & HADS anexiety \\
\hline PD stages & arson Correlation & $.907^{* *}$ & $.915^{* *}$ & $.456^{* *}$ & $.541^{* *}$ \\
& & & & & \\
\cline { 2 - 7 } & Sig. (2-tailed) & .000 & .000 & .000 & .000 \\
\hline \multicolumn{7}{|c|}{$* *$ Correlation is significant at the 0.01 level (2-tailed). } \\
\hline
\end{tabular}

There was high statistical significance between the three questionnaires and COPD stages as in table 7.

Table 8: Descriptive statistics of CCQ score domains.

\begin{tabular}{||l|l|l|l|l|c||}
\hline \hline CCQ domains & $\mathrm{N}$ & Iinimum & Iaximum & Mean \pm SD & P value \\
\hline CCQtotal & 300 & 6 & 56 & $28.30 \pm 13.684$ & .000 \\
\hline CCQsymptoms & 300 & 3 & 24 & $13.00 \pm 5.384$ & .000 \\
\hline CCQfunctional & 300 & 1 & 21 & $9.01 \pm 4.988$ & .000 \\
\hline CCQmental & 300 & 0 & 12 & $6.11 \pm 3.599$ & .000 \\
\hline
\end{tabular}


ISSN: 2536-9482 (Online) Fayoum University Medical Journal Elessawy et al., 2021,7(1), 920

As shown in table 8, there was high statistical significance between CCQ domains and COPD stages.

Figure 5: Mean CAT, CCQ total, HADS scores in COPD stages

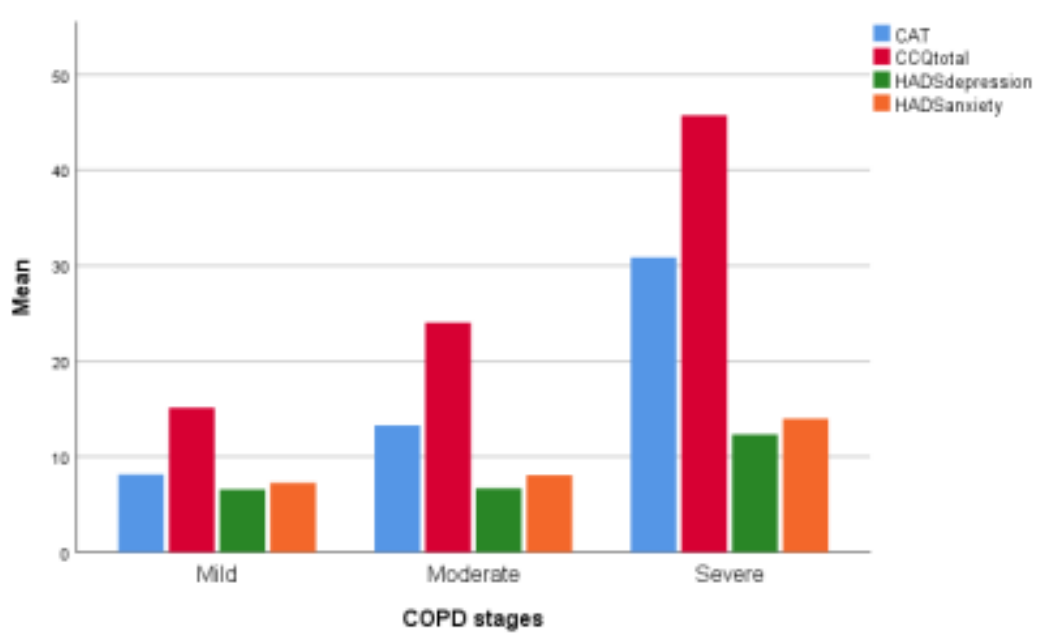

Figure 6: Progression of the three CCQ domains in the three stages of COPD

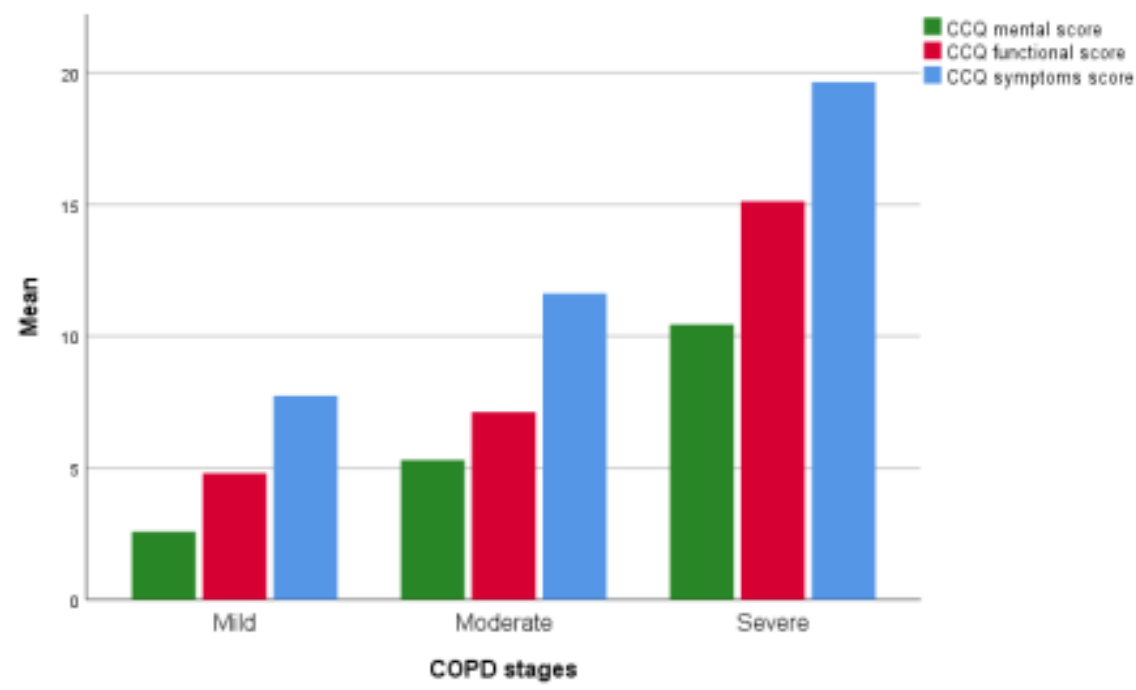

Figure 7: correlation between HADS score and Post FEV1 in \% 
ISSN: 2536-9482 (Online) Fayoum University Medical Journal Elessawy et al., 2021,7(1), 920

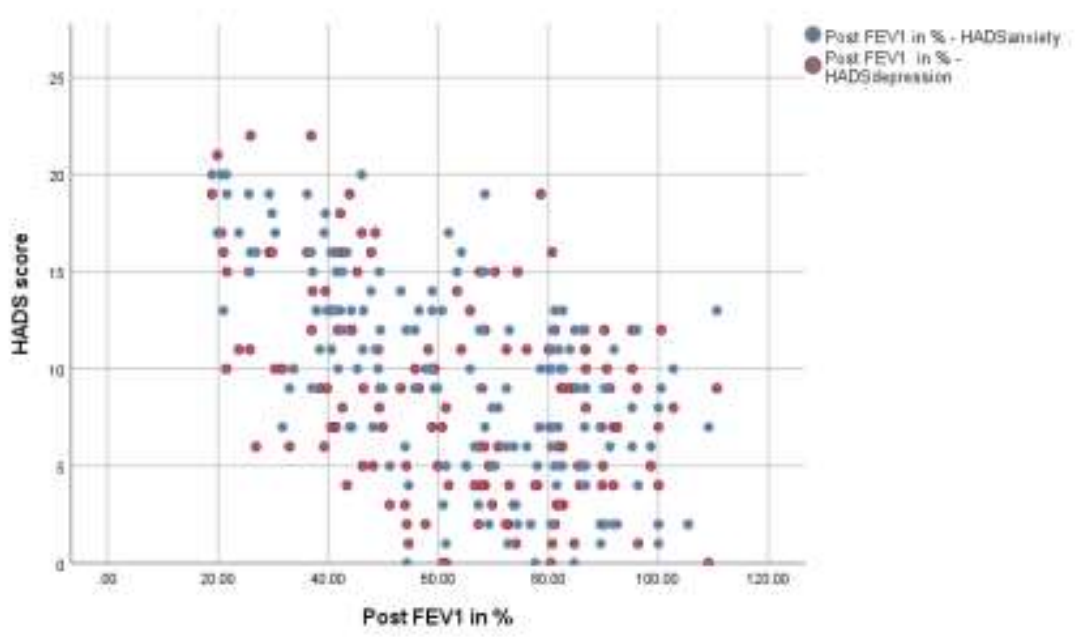

Figure 8: Depression and anxiety score in HADS to severity of COPD.

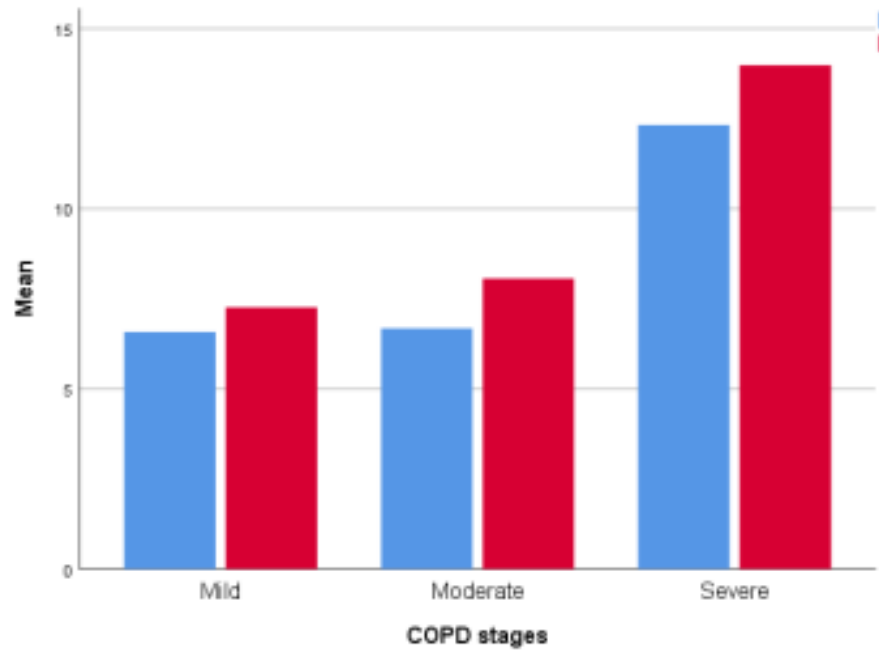

EADS depression scor

- HADS anviety score

\section{DISCUSSION}

COPD is a globally significant public health problem and is the second leading cause of mortality. As of 2016, the Global Burden of Disease (GBD) Study estimated that about 3 million people worldwide died of COPD. Also, COPD exerts a high economic burden on the individual as well as the health care system as it incurs two- to four-fold higher costs compared with asthma and ischemic heart disease [6].

Healthcare professionals may fail to recognize the burden of disease, as shown by under diagnosis and inadequate management. A key step in increasing awareness of the burden of COPD is obtaining comprehensive information about the impact of the disease on patients, the health service and society [7].

Our study included 300 candidate from Badr city and Fayoum governorate. The age selected was above 40 yrs.

Patients were divided into three groups based on GOLD staging system. Mean age in the mild group was 54.37, mean BMI was 2.63, mean FFMI was 19.48 and mean smoking index 
was 23.11. While in moderate group, mean age was 57.46, mean BMI was 27.12, mean FFMI was 19.00 and mean smoking was 61.19. In the severe group, mean age was 61.30, mean BMI was 26.51, mean FFMI was 18.16, while mean smoking index was 114.68 , all shown in table 1 and figures 12, 13, 14.

For assessing cachexia both BMI (Body Mass Index) and FFMI (Free Fat Mass Index) were measured and there correlation with COPD groups was estimated. There was no statistically significant difference or correlation between COPD severity and BMI, while there was statistically significant difference and a weak negative correlation between COPD severity and FFMI $(\mathrm{R}=-0.177, \mathrm{P}$ value $<0.01)$ which was expressed between mild and severe groups (Table 1, 2).

These data are compatible with data obtained from a cross sectional study done by Luo and his colleges in 2016. Results showed that malnutrition was identified in $48.5 \%$ of subjects and most prevalent in Group D (Group A: $41 \%$, Group B: $41 \%$, Group C: $31 \%$, and Group D: 62\%). The study found that, FFMI was significantly lower in Group D $(\mathrm{P}<.001)$ [8].

In our study smoking Index of each candidate was calculated and statistically studied and compared with other study variables. There was statistically significant difference between smoking index and COPD stages indicating that smoking index is higher in the more severe COPD stage

Dyspnea was assessed by analyzing mMRC scores obtained from candidates. In our results, there was a statistical significance between mMRC (Modified Medical Research Council) dyspnea grades and COPD stages (P value $<0.05)$ as shown in figure 19. Dyspnea is the most common symptom associated with poor quality of life in patients affected by Chronic Obstructive Pulmonary Disease (COPD).

This results comes with Paladini and his colleges in 2011 who studied the mMRC dyspnoea scale by telephone interview to monitor health status in elderly COPD patients on 200 elderly patients who had a physician diagnosis of COPD. The study concluded that the mMRC dyspnoea scale is a reliable index of disease severity and health status in elderly [9].

To assess general health status we collected data from CAT scores and CCQ score questionnaires. In our analysis, we found significant direct relationship between CAT score and COPD severity score increases with increasing severity of COPD (mean CAT score in mild stage $=8.14$, moderate $=13.28$, severe $=$ 30.86)

We found our results concordant with Ghobadi and his collegues in 2012 who made a 
study on 105 patients with stable COPD. Severity of airflow obstruction was assessed by standard spirometry and classified by the Global initiative for Obstructive Lung Disease (GOLD) criteria. Then, the impact of COPD on health status was assessed using CAT. The study found that there was correlation between the severity of smoking and GOLD classification was significant .There was a significant association between the FEV1\% predicted and total CAT score. They concluded that the relationship between CAT score FEV1\% predicted suggests that CAT is linked to severity of airflow limitation and GOLD classification in stable COPD patients. Health status as measured by CAT worsens with severity of airflow limitation [10].

In the current study, there was a stong positive correlation between CCQ total score and COPD severity. The more the COPD severity the higher the CCQ total score. The mean CCQ scores in mild stage $=15.12$, moderate $=24.04$, severe $=45.74$.

Our results match results obtained from a study done on 90 COPD patients by Tsiligianni and his colleges in 2012. Patients with severe COPD reported worse health status compared to milder subgroups. CAT and CCQ correlated significantly and both with the SGRQ. Both questionnaires exhibited a weak correlation with lung function [11]
Mental health was assessed by mental domain in CCQ questionnaire and by HADS score with its two domains depression and anxiety. In our study, there was significance and positive correlation between the two components of HADS score (depression and anxiety) and airflow limitation. Mean HADS depression score in mild stage $=6.58$, moderate $=6.68$, severe $=$ 12.32. Mean HADS anxiety score in mild stage $=$ 7.26, moderate $=8.06$, severe $=13.98$.

Our results agree with a study done by Di Marco and his colleges in 2006 included two hundred and two COPD patients. One hundred and fourteen sex- and age-matched healthy subjects were used as the control population. The prevalences of anxiety and depression were high (28.2\% and $18.8 \%$ ) in COPD even when it was of mild degree, compared to the control group, in which the prevalence of anxiety and depression were $6.1 \%$ and $3.5 \%$, respectively. Female patients had higher levels of anxiety and depression and worse symptom-related QOL. Dyspnea was more strongly correlated with depression in women than in men [12].

\section{Conclosion:}

\section{Based on the results of our study the following can be concluded:}

COPD carries high health, social, functional and psychological burden on the patient and burden is directly proportionate to COPD severity. 


\section{References}

1. Singh D, Agusti A, Anzueto A, Barnes PJ, Bourbeau J, Celli BR, et al. Global strategy for the diagnosis, management, and prevention of chronic obstructive lung disease: the GOLD science committee report 2019. Eur Respir $\mathbb{1 1}^{11}$ 2019; 53:1900164.

2. Halbert RJ, Natoli JL, Gano A, Badamgarav E, Buist AS, Mannino DM. Global burden of COPD: systematic review and meta-analysis. Eur Respir J 2006; 28:523-532.

3. Uzaslan E, Mahboub B, Beji M, Nejjari C, Tageldin MA, Khan JA, et al. The burden of chronic obstructive pulmonary disease in the Middle East and North Africa: results of the BREATHE study. Respir Med 2012; 106: S45S59.

4 Pauwels RA, Rabe KF. Burden and clinical features of chronic obstructive pulmonary disease (COPD). Lancet 2004; 364:613-620.

5 Choudhury G, Rabinovich R, MacNee W. Comorbidities and systemic effects of chronic obstructive pulmonary disease. Clin Chest Med 2014; 35:101-130.

6. Adhikari TB, Neupane D, Kallestrup P., 2018: Burden of COPD in Nepal. International journal of chronic obstructive pulmonary disease; 13 : 583.

7. Britton M, (2003): The burden of COPD in the UK: results from the Confronting COPD survey. Respiratory medicine; 97:S71-9.

8. Luo Y, Zhou L, Li Y, et al., 2016: Fat-free mass index for evaluating the nutritional status and disease severity in COPD. Respiratory care; 61(5):680-8.

9. Paladini L, Hodder R, Cecchini I, et al., 2010: The MRC dyspnoea scale by telephone interview to monitor health status in elderly COPD patients. Respiratory medicine; 104(7):1027-34.

10. Ghobadi H, Ahari SS, Kameli A, et al., 2012: The relationship between COPD assessment test (CAT) scores and severity of airflow obstruction in stable COPD patients. Tanaffos; 11(2):22.

1. Tsiligianni IG, van der Molen T, Moraitaki D, et al., 2012: Assessing health status in COPD. A head-to-head comparison between the COPD assessment test (CAT) and the clinical COPD questionnaire (CCQ). BMC pulmonary medicine; 12(1):20.

12. Di Marco F, Verga M, Reggente M, et al., 2006: Anxiety and depression in COPD patients: the roles of gender and disease severity. Respiratory medicine; 100(10):1767-74. 